\title{
Ki-67 labelling index and invasiveness among anterior pituitary adenomas: analysis of 103 cases using the MIB-1 monoclonal antibody
}

Luciano Mastronardi, Antonio Guiducci, Cristina Spera, Fabrizio Puzzilli, Fabio Liberati, Giulio Maira
Department of

Neurological Sciences, Unit of Neurosurgery, Civilian Hospital,

Terni, Italy

L Mastronardi

C Spera

F Puzzilli

G Maira

Institute of

Pathological Anatomy,

Civilian Hospital,

Terni

A Guiducci

F Liberati

Correspondence to: Dr Luciano Mastronardi, Via Archimede 120, 00197 Rome, Italy. email: mastro@tin.it

Accepted for publication 21 September 1998

\begin{abstract}
Aims-To investigate the relation between proliferative activity of anterior pituitary adenomas, quantified by the Ki-67 labelling index, and their invasive behaviour. Methods-Expression of Ki-67 was evaluated in 103 anterior pituitary adenomas consecutively operated on in a 36 month period and correlated with surgical evidence of invasiveness.

Results-Non-invasive $(n=65)$ and invasive $(n=38)$ adenomas were identified from surgically verified infiltration of sellar floor dura and bone. The wall of the cavernous sinus was infiltrated in 16 cases. Forty one adenomas were non-functioning and 62 functioning (24 prolactin, 21 growth hormone, 10 ACTH, seven mixed). The overall mean (SD) Ki-67 labelling index was 2.64 (3.69) per cent (median 1.5). The mean index was 3.08 (4.59) per cent in functioning and $1.97(1.78)$ per cent in non-functioning tumours; 5.47 (9.52) per cent in ACTH adenomas and 2.33 (2.42) per cent in others $(p=0.01) ; 3.71(5.17)$ per cent in invasive and $2.01(2.45)$ per cent in non-invasive adenomas $(p=0.027)$; and 5.58 (7.24) per cent in cavernous sinus infiltrating $v 2.10(2.39)$ per cent in cavernous sinus non-infiltrating adenomas $(p=$ $0.0005)$. To identify a value of labelling index beyond which adenomas should be considered invasive and another beyond which cavernous sinus infiltration should be suspected, normality $Q-Q$ plots were obtained: a threshold labelling index of $3.5 \%$ for invasive adenomas and of $5 \%$ for cavernous sinus infiltrating adenomas was defined, with statistically significant differences $(p=0.02$ and $p=0.004$, respectively).

Conclusions-The Ki-67 labelling index can be considered a useful marker in determining the invasive behaviour of anterior pituitary adenomas.

(f Clin Pathol 1999;52:107-111)
\end{abstract}

Keywords: invasiveness; Ki-67; pituitary adenomas

Anterior pituitary adenomas are usually histologically benign, even though in about a third of cases they infiltrate the surrounding tissues and, occasionally, the wall of cavernous sinus. ${ }^{1-11}$ This local "malignancy" adversely affects the surgical results and contributes to the possibility of relapse. In order to distinguish patients who can be considered surgically cured from patients at high risk of clinical and radiological recurrence, several experimental and clinicopathological studies have been undertaken to identify markers of tumour invasiveness. ${ }^{1-14}$

As with other neoplasms, determination of cell proliferation activity seems to be prognostically useful in anterior pituitary adenomas. $\mathrm{Ki}-67$, in particular, is a nuclear antigen expressed in the $G 1, S, G 2$, and $M$ phases of the cell cycle, ${ }^{15-21}$ and its labelling index, now characterised by the monoclonal antibody MIB- $1,{ }^{16}$ is widely considered to be a marker of cellular proliferation (growth fraction).

Our aim in this study was to investigate the relation between the proliferative activity of anterior pituitary adenomas, quantified by the $\mathrm{Ki}-67$ labelling index, and their invasive behaviour.

\section{Methods}

PATIENT CHARACTERISTICS

Between July 1994 and July 1997, 103 patients suffering from an anterior pituitary adenoma were operated on in our neurosurgical division. In all cases an evaluation of the Ki-67 labelling index of the surgical specimens was performed using the monoclonal antibody MIB- $1 .^{22}$

The patients' age ranged from 17 to 77 years (mean (SD) 42.8 (15.2) years, median 39): 10 cases (9.8 per cent) were under 25 years, 57 ( 55.3 per cent) were between 26 and 50 years, and 36 ( 34.9 per cent) were over 50 years. The $\mathrm{M} / \mathrm{F}$ ratio was 1:1.39 (60 females and 43 males). In 18 cases a previous operation had been performed elsewhere for pituitary adenoma, and in two cases two previous operations. A functioning adenoma, with clinically expressed hormonal dysfunction, was present in 62 patients (59 per cent): in 27 cases ( 43.5 per cent) the disturbances were related to high serum prolactin, in 25 (40.3 per cent) there was acromegaly, and in 10 (16.1 per cent) Cushing's syndrome. The preoperative serum hormone concentration was defined as the highest value before surgery. Reduced visual acuity or campimetric disturbances were present in 47 cases (45.6 per cent), mainly in patients with non-functioning adenomas (55.8 $v 38.7$ per cent). Raised intracranial pressure was observed in six cases ( 5.9 per cent).

In all cases the neuroradiological diagnosis was obtained by contrast enhanced cerebral computed tomography and magnetic resonance imaging (MRI); in 20 cases (19.4 per 


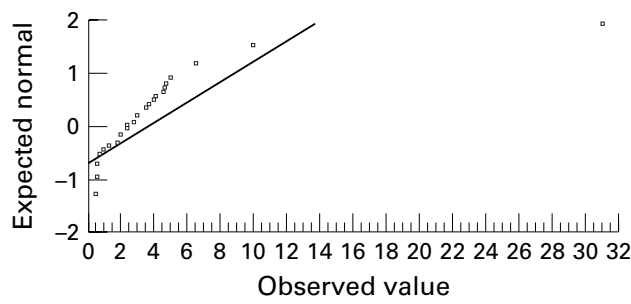

Figure 1 Normality plot of MIB-1 values in relation to invasiveness of sellar floor dura and bone.

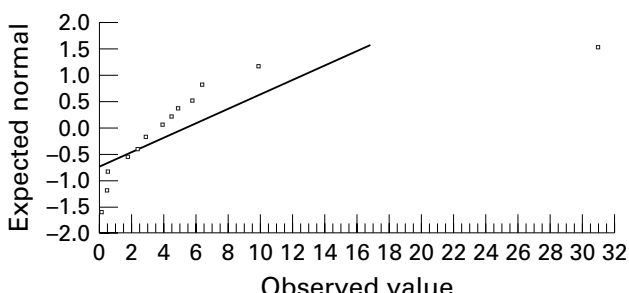

Observed value

Figure 2 Normality plot of MIB-1 values in relation to infiltration of the cavernous sinus.

cent) the tumour was a microadenoma $(\leqslant 10$ $\mathrm{mm}$ in diameter), in 23 (22.3 per cent) it was an intrasellar macroadenoma, in 29 (28.1 per cent) an intra-suprasellar macroadenoma, and in 31 (30.1 per cent) an intra-supra-parasellar macroadenoma.

A trans-sphenoidal approach was used in 98 cases (95.1 per cent), while a craniotomy was performed in five (4.9 per cent). Macroscopically total removal was achieved in 96 cases (93.2 per cent) and subtotal excision in seven (6.8 per cent). On the basis of surgically verified infiltration of the sellar floor dura and bone, we identified 65 (63.1 per cent) as noninvasive and 38 (36.9 per cent) as invasive. The wall of the cavernous sinus was infiltrated in 16 of the 38 cases with invasive adenomas (15.5 per cent of the group as a whole; 42.1 per cent of the invasive cases). Histological examination showed a typical anterior pituitary adenoma in all cases; on the basis of immunohistochemical staining we identified 37 (35.9 per cent) endocrine inactive tumours and 66 (64.1 per cent) active adenomas (24 prolactin, 21 growth hormone, 10 adrenocorticotrophic hormone (ACTH), three thyroid stimulating hormone (TSH), one follicle stimulating hormone (FSH), and seven mixed). Plurihormonal adenomas were classified according to the predominant endocrine symptoms (in four cases these were growth hormone related, and in three, prolactin related). Seventeen (62.9 per cent) of the 27 patients with prolactinomas or mixed adenomas with prevalent prolactin expression received preoperative medical treatment (bromocriptine).

DETERMINATION OF THE Ki-67 LABELLING INDEX (MIB-1 IMMUNOSTAINING)

The surgical specimens were routinely processed, fixed in neutral buffered formalin, and embedded in paraffin. To evaluate the $\mathrm{Ki}-67$ antigen staining, $5 \mu \mathrm{m}$ sections, previously mounted onto glass slides and dried, were incubated overnight at $4^{\circ} \mathrm{C}$ in the MIB- 1 antibody (Immunotech). ${ }^{16}$ Immunostaining was performed using the avidin-biotin-peroxidase method. Ten fields were selected in regions in which there were the highest concentrations of MIB-1 positive nuclei and were examined at high power $(\times 400)$; each field corresponded to 700 to 1000 cells, depending on the cellularity of the tumour specimen. Areas of necrosis, normal adenohypophysial cells, and endothelial cells were excluded from the evaluation. On the basis of a manual count of 1000 cells, the $\mathrm{Ki}-67$ labelling index was defined as the proportion of MIB-1 positive cells (dense brown precipitate restricted to the nuclei). The histopathological diagnosis and the $\mathrm{Ki}-67$ labelling index evaluation was performed by a single neuropathologist (AG).

\section{STATISTICAL ANALYSIS}

Computer assisted data analysis was performed with commercially available software (SPSS 6.0). The $\chi^{2}$ test ( 1 or 2 degrees of freedom, continuity correction) and analysis of variance (ANOvA) were used to identify the statistical significance of differences of $\mathrm{Ki}-67$ labelling index observed in relation to age, sex, previously operated $v$ newly diagnosed patients, functioning $v$ non-functioning adenomas, type of hormone secreted, presence or absence of preoperative visual disturbances, neuroradiologically estimated volume of tumour, surgical invasiveness, and infiltration of cavernous sinus. Values are expressed as the mean (SD); for each comparison, a $\mathrm{p}$ value was obtained and significance was assumed at $p \leqslant 0.05$. To identify a value of MIB-1 beyond which adenomas are likely to invade the sella floor dura and bone, and another beyond which cavernous sinus infiltration is likely, the expected normal values obtained from normality Q-Q plots (figs 1 and 2) were calculated as thresholds.

\section{Results}

A patient with a huge, invasive, cavernous sinus infiltrating adenoma died in the postoperative period from pulmonary embolism. Morbidity consisted of a cerebrospinal fluid fistula in five patients (4.8 per cent of 105 surgical procedures), treated successfully with spinal cerebrospinal fluid drainage through a lumbar subarachnoid catheter for three to four days.

In 18 cases the adenoma was functioning and invasive, in 44 functioning and noninvasive, in 20 non-functioning and invasive, and in 21 non-functioning and non-invasive $(p=0.022)$. Table 1 summarises the mean Ki-67 labelling indices of 103 anterior pituitary adenomas.

The overall mean (SD) Ki-67 labelling index was 2.64 (3.69) per cent (median 1.5; range 0 to 31 ). In five cases the labelling index was $\geqslant 10$ per cent. All these were secreting tumours (two ACTH, one growth hormone, one prolactin, and one growth hormoneprolactin), three were invasive, and two had infiltrated the cavernous sinus. In none of these cases was there any histological evidence of pituitary carcinoma.

There were no differences in the index in relation to age, sex, previous operations, presence of preoperative visual disturbances, or 
Table 1 Mean Ki-67 labelling indices (LI) of 103 anterior pituitary adenomas

\begin{tabular}{|c|c|c|c|c|}
\hline Cases & $n$ & Mean LI & $S D$ & $p$ Value \\
\hline All patients & 103 & 2.64 & 3.69 & \\
\hline$<25$ years & 10 & 2.67 & 2.01 & \\
\hline $25-50$ & 57 & 2.30 & 2.27 & \\
\hline$>50$ & 36 & 3.15 & 5.60 & 0.57 \\
\hline \multicolumn{5}{|l|}{ Previous operations } \\
\hline Yes & 20 & 2.48 & 2.30 & \\
\hline No & 83 & 2.68 & 4.05 & 0.83 \\
\hline \multicolumn{5}{|l|}{ Visual disturbances } \\
\hline Yes & 47 & 2.65 & 2.49 & \\
\hline No & 56 & 2.62 & 4.58 & 0.97 \\
\hline \multicolumn{5}{|l|}{ Functioning adenoma } \\
\hline Yes & 62 & 3.08 & 4.59 & \\
\hline No & 41 & 1.97 & 1.78 & 0.14 \\
\hline \multicolumn{5}{|l|}{$\begin{array}{l}\text { Endocrine active adenomas } \\
\text { (immunohistochemical staining) }\end{array}$} \\
\hline \multicolumn{5}{|l|}{ Type of hormone secreted } \\
\hline ACTH & 10 & 5.47 & 9.52 & \\
\hline FSH & 1 & 0.30 & - & \\
\hline GH & 21 & 2.18 & 2.50 & \\
\hline Mixed & 7 & 2.88 & 3.62 & \\
\hline PRL & 24 & 2.92 & 2.89 & \\
\hline TSH & 3 & 2.70 & 3.30 & 0.26 \\
\hline ACTH secreting adenomas & 10 & 5.47 & 9.52 & \\
\hline Other hormones/non-functional & 93 & 2.33 & 2.42 & 0.01 \\
\hline \multicolumn{5}{|l|}{$\mathrm{CT} / \mathrm{MRI}$ volume } \\
\hline Microadenoma (MA) & 20 & 2.57 & 1.84 & \\
\hline Intrasellar MA & 23 & 2.62 & 3.47 & \\
\hline Intra-suprasellar MA & 29 & 1.88 & 2.14 & \\
\hline Intra-supra-parasellar MA & 31 & 3.41 & 5.63 & 0.48 \\
\hline \multicolumn{5}{|l|}{ Invasiveness of surrounding tissues } \\
\hline Yes & 38 & 3.71 & 2.46 & \\
\hline No & 65 & 2.01 & 2.45 & 0.027 \\
\hline \multicolumn{5}{|l|}{ Infiltration of cavernous sinus } \\
\hline Yes & 16 & 5.58 & 7.24 & \\
\hline No & 87 & 2.10 & 2.39 & 0.0005 \\
\hline
\end{tabular}

ACTH, adrenocorticotrophic hormone; FSH, follicle stimulating hormone; $\mathrm{GH}$, growth hormone; PRL, prolactin; TSH, thyroid stimulating hormone.

neuroradiological estimation of the volume of the tumour. The Ki-67 labelling index was 3.08 (4.59) per cent in functioning tumours and 1.97 (1.78) per cent in the nonfunctioning tumours (NS). ACTH secreting adenomas had a higher labelling index than the others, at 5.47 (9.52) v 2.33 (2.42) per cent; $\mathrm{p}=0.01$. We found no significant differences among the other types of hormone releasing adenomas.

Preoperative treatment with bromocriptine had no effect on the labelling index in prolactin secreting adenomas or mixed adenomas with predominant prolactin expression.

Invasive adenomas had a $\mathrm{Ki}-67$ labelling index of 3.71 (5.17) per cent, $v 2.01$ (2.45) per cent in non-invasive tumours $(\mathrm{p}=0.027)$. The index was 5.58 (7.24) per cent in cavernous

Table 2 Comparison of invasive behaviour among 103 anterior pituitary adenomas with measurement of Ki-67 labelling index (LI; MIB-1), using a threshold value of $3.5 \%$ (see text)

\begin{tabular}{|c|c|c|}
\hline & Invasive & Non-invasive \\
\hline $\mathrm{LI} \leqslant 3.5 \%$ & 24 & 54 \\
\hline $\mathrm{LI}>3.5 \%$ & 14 & 11 \\
\hline Total & 38 & 65 \\
\hline $\mathrm{p}$ Value & \multicolumn{2}{|c|}{0.02} \\
\hline
\end{tabular}

Table 3 Comparison of cavernous sinus infiltration among 103 anterior pituitary adenomas with measurement of Ki-67 labelling index (LI; MIB-1), using a threshold value of $5 \%$ (see text)

\begin{tabular}{lll}
\hline & $\begin{array}{l}\text { Cavernous sinus } \\
\text { invasive }\end{array}$ & Non-invasive \\
\hline LI $\leqslant 5 \%$ & 10 & 80 \\
LI $>5 \%$ & 6 & 7 \\
$\begin{array}{l}\text { Total } \\
\text { p Value }\end{array}$ & 16 & 87 \\
\hline
\end{tabular}

sinus infiltrating and $2.10(2.39)$ per cent in non-infiltrating adenomas $(\mathrm{p}=0.0005)$.

We derived normality $Q-Q$ plots with the observed values of MIB-1 (figs 1 and 2). For invasive adenomas a threshold value of 3.5 per cent was identified and for cavernous sinus infiltrating adenomas, 5 per cent. The results obtained are summarised in tables 2 and 3 . The observed differences were statistically significant $(\mathrm{p}=0.02$ and $\mathrm{p}=0.004$, respectively).

After follow up ranging from six to 42 months, a reoperation for the treatment of a clinical and radiological tumour recurrence was performed in two patients after eight and 14 months, respectively. In these patients the first intervention was performed by a transsphenoidal approach and the second by craniotomy. At the first operation, the tumour was found to be invasive in both cases, and in one it infiltrated the cavernous sinus. In these cases the Ki-67 labelling indices of the first specimens were 6.1 per cent and 3.8 per cent, respectively. Both the relapsed tumours had invaded sellar floor dura and bone and the wall of the cavernous sinus; the Ki-67 labelling indices of the recurrent tumours were 10 per cent and 5.5 per cent, respectively.

\section{Discussion}

A tendency for juxtasellar expansion of some anterior pituitary adenomas has been observed from the first reports. ${ }^{23-25}$ In the early 1970 s, Jefferson $^{26}$ identified a group of pituitary tumours that he defined "invasive" adenomas, in which an extrasellar spread occurred, sometimes with infiltration of the cavernous sinus. Martins et al similarly defined an invasive pituitary adenoma as a tumour which extends beyond its capsule or involves contiguous structures. $^{7}$

The incidence of invasiveness among these tumours varies among different anterior pituitary adenoma subtypes ${ }^{9}$ and also in relation to the criteria used for assessment. Infiltrating behaviour has been demonstrated surgically in about 35 per cent of pituitary adenomas and histologically (by microscopic infiltration of dura mater) in about 90 per cent. ${ }^{1-11}$ From our experience and in agreement with Thapar et $a l,{ }^{11}$ the most reliable criterion of invasiveness seems to be the surgeon's impression during the operation.

Until now, unfortunately, no routine markers have been available to identify invasive anterior pituitary adenomas. The usual morphological findings typical of histological aggressiveness are quite uncommon among these neoplasms. ${ }^{10}{ }^{11}$ Recently, however, several cell cycle specific nuclear antigens have been recognised, using various immunohistochemical methods, which allow reliable evaluation of tumour growth characteristics. One in particular, $\mathrm{Ki}-67$, is a nuclear antigen readily identified by the monoclonal antibody MIB- $1,{ }^{16}$ and is typically expressed in proliferating cells during the G1, S, G2, and $M$ phases of the cell cycle. ${ }^{15-21}$ It has been found to be useful in assessing several human neoplasms,${ }^{26-29}$ providing information about the cell proliferation rate and thus about long term prognosis. 
Table 4 Proposal for a grading system for invasiveness of pituitary adenomas in relation to mean Ki-67 labelling indices (LI) observed in 103 cases, and in one case with pituitary carcinoma (not included in this report)

\begin{tabular}{llc}
\hline Grade & & Mean Li-67 LI \\
\hline 0 & Non-invasive pituitary adenomas & $2.01 \%$ \\
1 & Invasive pituitary adenomas & $3.71 \%$ \\
2 & Cavernous sinus infiltrating & $5.58 \%$ \\
& pituitary adenomas & $36.00 \%$ \\
\hline
\end{tabular}

MIB-1 immunostaining is a practical method that can be used in the routine histological evaluation of brain tumours and also of anterior pituitary adenomas. Though automated analysis is faster and easier, manual cell counting is equally reliable ${ }^{11}$ and is applicable everywhere. A high growth fraction expressed by a high $\mathrm{Ki}-67$ labelling index should suggest the need for careful clinical and radiological follow up. ${ }^{30}$

To date, only a few investigators have reported their experience in evaluating anterior pituitary adenoma growth fraction based on the expression of the $\mathrm{Ki}-67$ antigen, using both formalin fixed tissue and in vitro cell culture. ${ }^{124-611131531}$ Landolt et al examined the growth rate of 31 pituitary adenomas, ${ }^{13}$ the Ki-67 labelling index ranged from 0.1 to 3.7 per cent, with higher values in functioning adenomas (especially the ACTH secreting type) and in invasive adenomas verified radiologically, surgically, and histologically. In a series of 62 cases, Knosp et al reported proliferation activity ranging from 0.1 to 2.8 per cent, with a higher Ki-67 labelling index $(p<0.05)$ in adenomas with histological evidence of dural infiltration. ${ }^{15}$ Daita et al evaluated the correlation between histological invasiveness of the sellar floor dura and proliferative activity in 31 pituitary adenomas, showing a higher MIB-1 positive ratio with dural invasion than with non-invasive tumours $(p<0.05) .{ }^{4}$ Asano et al evaluated the MIB-1 index in 63 surgically removed anterior pituitary adenomas ${ }^{1}$; values ranged from 0 to 6.5 per cent, with low values in growth hormone secreting tumours and high values in prolactin secreting tumours. Preoperative treatment with bromocriptine had no effect on the labelling index values. In our series we also found that growth hormone secreting adenomas had a low Ki-67 labelling index, whereas prolactin secreting tumours had a mean index above the mean for the cohort as a whole (table 1). Shibuya et al reported their experience of 65 pituitary adenomas in which, among other tests, the Ki-67 expression was evaluated ${ }^{31}$; they obtained higher labelling index values in recurrent, non-functioning, and $\mathrm{ACTH}$ secreting adenomas. We confirmed the latter finding in our series (table $1, p=0.01$ ), as have other investigators, ${ }^{611} 15$ and the finding of a high mean Ki-67 labelling index in recurrent adenomas was also shown by Ekramullah et al. ${ }^{5}$ These latter workers evaluated MIB-1 positivity in 14 regrowing non-functioning pituitary adenomas and 19 cases without clinical or MRI signs of tumour recurrence; they observed a higher index $(p<0.01)$ in the group with recurrence (mean 0.86 per cent) than in the "cured" cases (mean 0.23 per cent). Though in our series we did not find any difference in Ki-67 labelling index between the 20 patients previously operated on elsewhere and the 83 newly diagnosed patients (table 1), the indices in the two patients who presented with recurrences were 6.1 per cent and 3.8 per cent, respectively, while in relapsed tumours invading the surrounding tissues and the cavernous sinus the indices were higher (10 per cent and 5.5 per cent, respectively). We cannot rule out the possibility that some of the patients in our series who underwent reoperation did not have a true recurrence of an aggressive tumour but regrowth of the residual portion of the tumour, which was not completely extirpated at the original operation. This would invalidate the low mean Ki-67 labelling index observed in the reoperated group (table 1 ).

In a series of 70 anterior pituitary adenomas and seven carcinomas, Thapar et al reported mean MIB-1 values of 1.37 per cent in non-invasive adenomas, 4.66 per cent in invasive adenomas, and 11.91 per cent in pituitary carcinomas $(p<0.01) .{ }^{11}$ As in our findings (table 1), functioning adenomas in their series had a higher $(p=0.03)$ mean labelling index (3.25 per cent) than nonfunctioning adenomas (2.06 per cent). These investigators established a value of 3 per cent as the threshold labelling index for distinguishing non-invasive from invasive anterior pituitary adenomas. ${ }^{11}$ In our study, using normal Q-Q plots of observed MIB-1 values (figs 1 and 2), we identified two different threshold values of the $\mathrm{Ki}-67$ labelling index, one for invasive adenomas (3.5 per cent) and one for cavernous sinus infiltrating adenomas ( 5 per cent). The results obtained with these thresholds are summarised in tables 2 and 3, and the differences observed were statistically significant $(\mathrm{p}=0.02$ and $p=0.004$, respectively). From the mean Ki-67 labelling indices, it appears that adenomas with surgically verified infiltration of the sellar floor dura and bone are less aggressive than those that also infiltrate the wall of cavernous sinus; the latter probably represents a second level of invasiveness (table 4), though the biological significance of this difference remains unclear. Thus an index ranging between 3.5 and 5 per cent could suggest infiltrating behaviour, while an index above 5 per cent also suggests the possibility of infiltration of the cavernous sinus wall. In both circumstances, careful clinical, hormonal, and MRI follow up seems necessary so as to identify the predicted recurrence of the tumour as early as possible.

CONCLUSION

It is well recognised that about one third of pituitary adenomas are "invasive," with extension beyond the capsule and involvement of contiguous structures, sometimes with infiltration of the cavernous sinus. ${ }^{791126}$ Evaluation of the growth fraction-identified by Ki-67 nuclear antigen, which is easily detected with MIB-1 monoclonal antibody-seems to provide additional insight into the infiltrative 
behaviour of the tumour, and is thus a marker of possible recurrence. It is the experience of most neurosurgeons that even apparently noninvasive adenomas that seem to have been completely removed sometimes recur. Several studies, including our own, suggest that a high Ki-67 labelling index indicates that the tumour is destined for postoperative relapse.

1 Asano K, Kubo O, Tajika Y, et al. The relationship between cell proliferation and secretory activity in pituitary
adenomas. A review of 63 cases. No To Shinkei 1996;48:543-9

2 Atkin SL, Green VL, Hipkin LJ, et al. A comparison of proliferation indices in human anterior pituitary adenomas using formalin-fixed tissue and in vitro cell culture. 7 Neurosurg 1997;87:85-8.

3 Buchfelder M, Fahlbusch R, Adams EF, et al. Proliferation parameters for pituitary adenomas. Acta Neurochir Suppl (Wien) 1996;65:18-21.

4 Daita G, Yonemasu Y. Dural invasion and proliferative potential of pituitary adenomas. Neurol Med Chir 1996;36: 211-14.

5 Ekramullah SM, Saitoh Y, Arita N, et al. The correlation of Ki-67 staining indices with tumour doubling times in regrowing non-functioning pituitary adenomas. Acta Neurochir (Wien) 1996;138:1449-55.

6 Knosp E, Kitz K, Steiner E, et al. Pituitary adenomas with parasellar invasion. Acta Neurochir Suppl (Wien) 1991;53 65-71.

7 Martins AN, Hayes GJ, Kempe LG. Invasive pituitary adenomas. $\mathcal{F}$ Neurosurg 1965;22:268-76.

8 Pernicone PJ, Scheithauer BW. Invasive pituitary adenomas and pituitary carcinomas. In: Lloyd RV, ed. Surgical pathology of the pituitary gland. Philadelphia: WB Saunders, 1993: 121-36.

9 Scheithauer BW, Kovacs KT, Laws ER, et al. Pathology of invasive pituitary tumors with special reference to funcinvasive pituitary tumors with special reference

10 Selman WR, Laws ER, Scheithauer BW, et al. The occurrence of dural invasion in pituitary adenomas. $\mathcal{F} \mathrm{Neu}-$ occurrence of dural invas
rosurg 1986;64:402-7.

11 Thapar K, Kovacs K, Scheithauer BW, et al. Proliferative activity and invasiveness among pituitary adenomas and carcinomas: an analysis using the MIB-1 antibody. Neurosurgery 1996;38:99-107.

12 Gandour-Edwards R, Kapadia SB, Janecka IP, et al. Biologic markers of invasive pituitary adenomas involving the sphenoid sinus. Mod Pathol 1995;8:160-4.

13 Landolt AM, Shibata T, Kleihues P. Growth rate of human pituitary adenomas. F Neurosurg 1987;67:803-6.

14 Nagashima T, Murovic JA, Hoshino T, et al. The proliferative potential of human pituitary tumors in situ. 7 Neurosurg 1986;64:588-93.
15 Knosp E, Kitz K, Perneczky A. Proliferation activity in pituitary adenomas: measurement by monoclonal antibody Ki-67. Neurosurgery 1989;25:927-30.

16 McCormick D, Chong H, Hobbs C. Detection of the Ki-67 antigen in fixed and wax-embedded sections with the monoclonal antibody MIB-1. Histopathology 1993;22:35560 .

17 Morimura T, Kitz K, Stein H. Determination of proliferative activities in human brain tumor specimens: a comparison of three methods. $\mathcal{F}$ Neurooncol 1991;10:1-11.

18 Parkins CS, Darling JL, Gill SS. Cell proliferation in serial biopsies through malignant brain tumors: measurement using Ki-67 antibody labelling. Br f Neurosurg 1991;5:28998.

19 Shiraishi T. Cell kinetic analysis of brain tumors using the monoclonal antibody Ki-67: in vitro and in situ study. Acta Med Okayama 1990;44:197-201.

20 Tsanaclis AM, Robert F, Michaud J. The cycling pool of cells within human brain tumors: in situ cytokinetics using the monoclonal antibody Ki-67. Can f Neurol Sci 1991;18: $12-17$.

21 Zuber P, Hamou MF, de Tribolet N. Identification of proliferating cells in human gliomas using the monoclonal antibody Ki-67. Neurosurgery 1988;22:364-8.

22 Brown DC, Gatter KC. Monoclonal antibody Ki-67: its use in histopathology. Histopathology 1990;17:489-503.

23 Henderson WR. The pituitary adenomata. A follow-up study of the surgical results in 338 cases (Dr Harvey Cushing's series). Br F Surg 1939;26:811-921.

24 Jefferson G. Extrasellar extension of pituitary adenomas. Proc R Soc Med 1940;33:433-58.

25 Trumble HC. Pituitary tumours. Observations on large tumours which have spread widely beyond the confines of the sella turcica. Br $\mathcal{F}$ Surg 1951;39:7-24.

26 Jefferson $\mathrm{G}$. The invasive adenomas of the anterior pituitary, 2nd ed. Springfield, Illinois: Charles C Thomas, 1972:5660.

27 Hall PA, Woods AL. Immunohistochemical markers of cellular proliferation: achievements, problems, and prospects. Cell Tissue Kinet 1990;23:505-22.

28 Hops NJ, Bremm J, Bohl J, et al. Image analysis of proliferating cells in tumors of the human nervous system: an immunohistological study with the monoclonal antibody Ki-67. Neurosurgery 1994;35:917-23.

29 Wintzer HO, Zipfel I, Schulte-Monting J, et al. Ki-67 mmunostaining in human breast tumours and its relationship to prognosis. Cancer 1990;67:421-8.

30 Hsu DW, Hakim F, Biller BMK, et al. Significance of proliferating cell nuclear antigen index in predicting pituitary adenoma recurrence. 7 Neurosurg 1993;78:753-61.

31 Shibuya M, Saito F, Miwa T, et al. Histochemical study of pituitary adenomas with $\mathrm{Ki}-67$ and anti-DNA polymerase alpha monoclonal antibodies, bromodeoxyuridine labeling, and nucleolar organizer region counts. Acta Neuropathol (Berl) 1992;84:178-83. 